\title{
ORIGINAL
} ARTICLES

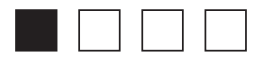

\section{Sexual Harassment and Gender Bias in Family Medicine: Divergent Experiences of Men and Women}

Mechelle Sanders, PhD; Colleen T. Fogarty, MD, MSc; Holly Ann Russell, MD, MS; Kevin Fiscella, MD, MPH; Anne Nofziger, MD; Elizabeth Naumburg, MD; Tziporah Rosenberg, PhD; Susan McDaniel, PhD

\begin{abstract}
BACKGROUND AND OBJECTIVES: Awareness of sexual harassment (SH), gender bias (GB), and gender discrimination (GD) has spread throughout popular culture and has been highlighted at universities across the United States. More nuanced data is needed to inform policies that address these issues. However, there are currently limited qualitative studies examining the nature of $\mathrm{SH}, \mathrm{GB}$, and GD in academic medicine, particularly family medicine.
\end{abstract}

METHODS: In 2018, we conducted a series of gender-specific focus groups with faculty and residents in a department of family medicine (DFM) to understand their experiences with and responses to SH, GB, and GD. The focus groups were transcribed verbatim. We used immersion-crystallization and an adapted SH Experiences model to review the transcripts and identify patterns or themes during the immersion process.

RESULTS: Participants identified the potential for patients, colleagues, faculty, and themselves as perpetrators and victims of $\mathrm{SH}, \mathrm{GB}$, and GD. Results suggested that GB was often implicit. SH was experienced verbally and physically. Women participants, especially, reported that both SH and GB occurred frequently and had lasting psychological effects. Gender, age, and position (faculty vs trainee) moderated SH and GB experiences. The effects seemed to be mediated by moral distress.

CONCLUSIONS: This study emphasizes the importance of recognizing differences in experiences across gender, age, and position of SH, GB, and GD in academic family medicine. Our findings can be leveraged to develop antiharassment policies and set cultural expectations.

(Fam Med. 2022;54(3):176-83.)

doi: 10.22454/FamMed.2022.331576

specially after \#MeToo, sexual harassment ( $\mathrm{SH})$, gender bias (GB), and gender discrimination (GD) have been reported within academic medicine across discipline and academic position. Ceppa et al found that among attending surgeons, $81 \%$ of women vs $46 \%$ of men had experienced sexual harassment. ${ }^{1}$ At a large academic medical center, the majority of faculty women $(82.5 \%)$ and faculty men $(65.1 \%)$ experienced at least one incident of sexual harassment from staff, students, or faculty within the previous year. ${ }^{2} \mathrm{~A}$ systematic review of $\mathrm{SH}$ and discrimination found a prevalence of verbal harassment ranged from $3 \%$ to $28 \%$ among medical trainees. ${ }^{3}$ Stratton et al found that GD and SH influenced medical trainees' choice of specialty and residency program rankings. ${ }^{4}$ These experiences have implications for emotional well-being and long-term career outcomes.

To our knowledge, few qualitative studies of SH, GB, and GD in academic medicine exist. ${ }^{4}$ We previously described barriers and facilitators to reporting and responding to $\mathrm{SH}$ and GB in family medicine (FM) ${ }^{6}$ We found that one of the strongest facilitators for breaking the silence around these experiences was a culture that supported discussion and action around $\mathrm{SH}$ and GB. ${ }^{6,7}$ Wendling et al's supporting commentary noted the

need to shine the light on our institutions and understand how our people-all of our people-are being treated, for to face that truth is to take our first step toward change. ${ }^{8}$

From the Department of Family Medicine, University of Rochester Medical Center, Rochester, NY (Drs Sanders, Fiscella, Naumburg, Rosenberg, and McDaniel); Department of Family Medicine, University of Rochester School of Medicine and Dentistry, Rochester, NY (Drs Fogarty, Russell, and Nofziger); and Institute for the Family in Psychiatry, University of Rochester Medical Center, Rochester, NY (Drs McDaniel and Rosenberg). 
The literature on $\mathrm{SH}$ among physicians uses primarily quantitative methods and characterizes the frequency and type of harassment ${ }^{3}$ but provides little context or nuance. Further, the few qualitative studies tended to include homogenous gender (primarily women) and position (trainees or faculty) samples. We need a more nuanced and comprehensive understanding of the nature of SH, GB, and GD experienced in FM across gender and position in order to develop all-inclusive strategies and policies that mitigate these issues.

In this paper, we present the lived experiences of our participants in order to begin to address this need. We use qualitative data to better understand and characterize the nature, pervasiveness, and responses to $\mathrm{SH}, \mathrm{GB}$, and GD between and within men and women faculty and residents in a department of FM.

\section{Methods}

We conducted focus groups (FGs) with faculty and residents in our department of FM to understand their experiences with and responses to SH, GB and GD. The University of Rochester's Institutional Review
Board deemed this study exempt (RSRB00072684). We used the consolidated criteria for reporting qualitative research as a guide to report the study findings. ${ }^{7}$

Research team members (S.M., K.F., H.R., T.R., E.N., A.N.) facilitated the faculty groups. The chief residents facilitated the resident groups out of concern that residents may feel vulnerable sharing their experiences with faculty. All participants self-selected into the FGs divided by gender (women or men) and position (resident or faculty). None of the FGs were nonbinary.

\section{Participants}

We conducted six FGs. There were four, 1-hour faculty FGs that consisted of attending physicians, behavioral health faculty, and nurse practitioners, at different career stages. The two, 2-hour resident FGs consisted of physician residents (Table 1). The FG invitation emphasized that participation was voluntary, confidential, and nonremunerated. All faculty and residents were invited to participate.

The facilitator's gender was concordant with the FG they facilitated. Facilitators began the sessions with a review of voluntary consent for participation, assurance of confidentiality, and the expectation of confidentiality among participants. The semistructured interview began with the definitions of $\mathrm{SH}, \mathrm{GB}$, and GD from the US Equal Employment Opportunity Commission. ${ }^{9}$ Facilitators first asked about experiences with $\mathrm{SH}, \mathrm{GB}$, and GD with patients, which we felt to be a safer conversation than experiences with colleagues or supervisors. We concluded by asking more generally about any other experiences with $\mathrm{SH}, \mathrm{GB}$, or GD they would like to share. Our semistructured interview guide has been previously reported. ${ }^{6}$ We audio recorded each FG and had them professionally transcribed anonymously.

\section{Identification of Codes and Categories}

We used an immersion-crystallization process whereby we immersed ourselves in the data, reflected collectively on the analysis experience, and identified patterns or themes noticed during the immersion process..$^{10}$ A concept was considered a code if it was noted more than once and present in at least two transcripts.

Figure 1: Adapted Version of Fitzgerald et al's Conceptual Model of SH Experiences and Four Competing Models of Harassment Framework

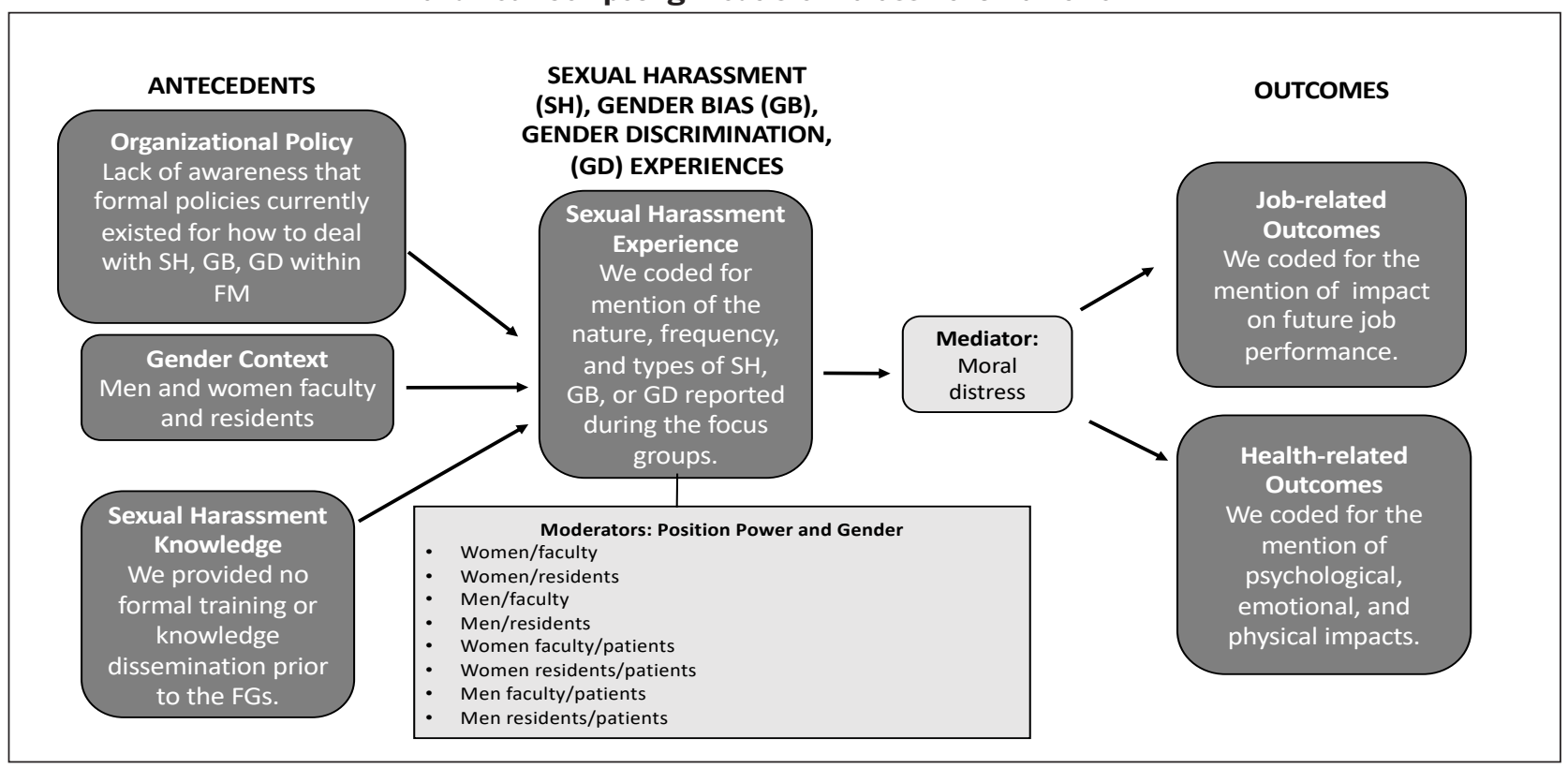


Table 1: Composition of the Focus Groups

\begin{tabular}{|c|c|c|c|c|}
\hline Group Mix & General Flow of Discussion & $\begin{array}{l}\text { Gender and Role } \\
\text { of Facilitators }\end{array}$ & $\begin{array}{l}\text { Total No. } \\
\text { of Focus } \\
\text { Grups }\end{array}$ & $\begin{array}{c}\text { No. of } \\
\text { Participants Per } \\
\text { Focus Group }\end{array}$ \\
\hline Women faculty & \multirow{4}{*}{$\begin{array}{l}\text { - Remind participants that FG is voluntary, } \\
\text { nonremunerated, and confidential } \\
\text { - Definition of SH, GD, and GB from } \\
\text { US Equal Employment Opportunity } \\
\text { Commission* } \\
\text { - Provide an opportunity for participants } \\
\text { to share experiences of SH, GD, and } \\
\text { GB that they may have experienced or } \\
\text { witnessed with patients } \\
\text { - Provide an opportunity for participants } \\
\text { to share experiences of SH, GD, and } \\
\text { GB that they may have experienced or } \\
\text { witnessed with colleagues (and or faculty } \\
\text { for the resident groups) }\end{array}$} & Women faculty & 2 & \multirow{4}{*}{$\mathrm{n}=7-12$} \\
\hline Men faculty & & Men faculty & 2 & \\
\hline $\begin{array}{l}\text { Women } \\
\text { residents }\end{array}$ & & Woman chief resident & 1 & \\
\hline Men residents & & Man chief resident & 1 & \\
\hline
\end{tabular}

Abbreviations: FG, focus group; SH, sexual harrassment; GD, gender discrimination; GB, gender bias.

* US Equal Employment Opportunity Commission. Preventing employment discrimination against lesbian, gay, bisexual or transgender workers (brochure). US Equal Employment Opportunity Commission. Published 2014. Accessed November 23, 2021. https://www.eeoc.gov/laws/guidance/ preventing-employment-discrimination-against-lesbian-gay-bisexual-or-transgender

We adapted Fitzgerald et al's model by incorporating known moderators of reported experiences with $\mathrm{SH}, \mathrm{GB}$, and GD, and a mediator of reported outcomes. We used our adapted model to explain differences in reported experiences based at the intersections of gender and/or position power among FG participants.

The team met regularly to develop the coding structure; discuss additional themes, gaps or discordances; and review continued strategies for analyses. We approved the final coding structure after four iterations. Once consensus on the coding structure occurred, each transcript was read and independently coded by two study team members. Each coder entered their independent codes into a MAXQDA database where the codes were summarized and collated for analyses. We member-checked ${ }^{9}$ the validity of our findings with faculty during regularly scheduled faculty meetings. Study team members did not code any of the transcripts for groups they facilitated. We used Fitzgerald et al's SH Experiences model as a guiding framework to map antecedents and outcomes related to SH, GB, and GD. We adapted the model by incorporating known moderators of reported experiences with SH, GB, and GD, and a mediator of reported outcomes (Figure 1)..$^{12}$ Specifically, our model was used to explain differences in reported experiences based on the intersections of gender (men vs women) ${ }^{13}$ and/or position-power (trainee vs faculty vs patient vs age), as well as the impact of moral distress ${ }^{14}$ (ie, when clinicians cannot accomplish what they believe to be ethically appropriate actions) on outcomes. ${ }^{15}$ In medical training, trainees are typically, although not always, younger than attending clinicians. It was difficult to separate the effect of age and of power status, so we present the combination of these as "position-power."

\section{Results}

\section{Participants}

Twenty-eight faculty and 24 residents took part in the six FGs (Table 1). We did not collect demographic information to ensure anonymity. Professional role representation of the FG participants was comparable to the overall DFM roles (Table 2).

\section{Analyses: Codes and Themes}

We identified four main themes: (1) SH and GB occurred frequently to women, particularly while in training, (2) GB was often implicit and disproportionately affected women, (3) SH had differential impact by age (of the offender or offendee) and gender (of the offender or offendee), and (4) GB and SH left lasting effects, sometimes mediated by moral distress. Illustrative quotes related to each code are shown in Table 3. Examples of quotes related to the more specific themes are listed in Table 4 . We observed variation within some themes based on the gender of the offendee and the type of offender (patient, colleague/faculty). While the transcripts were deidentified, the gender of offender and offendee were often stated or obvious from context.

Theme 1: SH and GB Occurred Frequently to Women, Particularly While in Training. All women FGs reported frequent firsthand experiences of $\mathrm{SH}$ and GB. Women faculty and residents had similar experiences, but faculty reported more frequent SH when they were younger and/or in training.

Sometimes when I think about this, I feel like this happens literally almost every single day. I feel like personally I get very numb to it. Just happened to me yesterday 
Table 2: Department of Family Medicine Clinician Characteristics

\begin{tabular}{|l|c|l|}
\hline & \multicolumn{1}{|c|}{ DFM, Overall } & \multicolumn{1}{|c|}{ DFM, Focus Group Participants } \\
\hline Faculty & $\mathrm{N}=47$ & $\mathrm{~N}=28$ (59.6\% participation rate) \\
\hline Residents & $\mathrm{N}=30$ & $\mathrm{~N}=24(80 \%$ participation rate $)$ \\
\hline Total & $\mathrm{N}=77$ & $\mathrm{~N}=52(67.5 \%$ participation rate $)$ \\
\hline
\end{tabular}

Abbreviation: DFM, department of family medicine.

Table 3: Examples of the Coding Structure

\begin{tabular}{|l|l|l|}
\hline \multicolumn{1}{|c|}{ Category } & \multicolumn{1}{|c|}{ Code } & \multicolumn{1}{c|}{ Exemplary Quote } \\
\hline Lived experience & Witnessed directly & $\begin{array}{l}\text { "I see it in residents. I remember a resident that I was watching for direct } \\
\text { observation, for primary care counseling, and the patient very explicitly made a } \\
\text { number of comments about her, and the resident handled it beautifully and said, } \\
\text { 'That's not appropriate. We're not gonna talk about those things. If you can't stop } \\
\text { talking about those things, I'm gonna have to step out of the room." }\end{array}$ \\
\hline $\begin{array}{l}\text { Perceived } \\
\text { frequency }\end{array}$ & $\begin{array}{l}\text { Frequency of } \\
\text { harassment }\end{array}$ & $\begin{array}{l}\text { "I mean, there's things like ... the labor and delivery resident ... had a little } \\
\text { wooden box that had a faux vaginal canal that you could practice doing vaginal } \\
\text { exams on and I can't even tell you how many jokes there were about the vagina } \\
\text { in a box. It was just like a common center of sexualized joking." }\end{array}$ \\
\hline $\begin{array}{l}\text { Behavioral } \\
\text { responses }\end{array}$ & $\begin{array}{l}\text { Tried not to show it } \\
\text { bothered you }\end{array}$ & $\begin{array}{l}\text { "And I tried to laugh it off, tried to push it off. But I felt that I didn't deal with it } \\
\text { very well, and I told faculty that he [the patient] made me freaked out." }\end{array}$ \\
\hline $\begin{array}{l}\text { Affective } \\
\text { responses }\end{array}$ & $\begin{array}{l}\text { "Yeah, it's true. I harbor guilt to this day about it, though, because I never said } \\
\text { anything to anybody, that that was a thing. And, only later, I found out much } \\
\text { later, I found out that it was a known dynamic, shall we say." }\end{array}$ \\
\hline
\end{tabular}

when I was in a patient room. [Resident woman]

Most of my examples are from when I was younger also, but I don't think that's because it doesn't happen now. [Faculty woman]

There were few firsthand examples of $\mathrm{SH}$ and $\mathrm{GB}$ reported in the men's FG. However, the men did comment on how frequently these experiences occurred among women trainees.

... persistent misogyny... there's a particular faculty member in a prominent position ... who just does this over and over again. And students will tell you this. I mean, it's just ... over and over and over and over and over again. [Faculty man]

Dozens of times. Precepting. Patients frequently comment ... I'll say something like, 'You've got a really good doctor,' and [they] say, 'She's really hot, too,' or, 'She's really good looking,' or, 'She dresses real nice ...' [Faculty man]
Theme 2: GB Was Often Implicit and Disproportionately Impacted Women. Many participants described experiences where patients assumed the man in the room was the physician, regardless of their actual position. There was also a tendency among patients to attribute female stereotyped gender-roles to women.

We walked in this patient's room ... The person addressed me as 'doctor,' and said to [the woman colleague], 'Are you the TV lady?' [Faculty man]

... when you walk in as a team with a female attending and perhaps a male medical student or resident and the patients will almost always address the man. [Resident woman]

A faculty woman described situations where women's ideas are appropriated by men.

... some guy later makes your suggestion. And I say, 'Well, I'm glad you agree with (woman colleague) She mentioned that about $10 \mathrm{~min}$ utes ago ...' [Faculty woman]

Theme 3: SH Had Differential Impact by Age (of the Offender or Offendee) and Gender (of the Offender or Offendee). Verbal SH was common, including statements with sexual connotations. Examples of verbal harassment included jokes, sexist remarks, and comments on physical appearance. Women commented on being distressed when being referred to with diminutive names such as "sweetness" and "cutie."

Faculty women mentioned that as they grew older and rose in academic rank, the instances of $\mathrm{SH}$ declined.

... when you have gray hair, you don't get hit on as much anymore ... it definitely becomes protective. [Faculty woman]

There was some disagreement among participants about what constitutes $\mathrm{SH}$ when the situation involved age discordance (eg, a younger 
Table 4: Examples of Codes Related to Each Theme

\begin{tabular}{|c|c|}
\hline Theme & Exemplary Quote(s) \\
\hline \multirow{3}{*}{$\begin{array}{l}\text { Theme 1: Sexual harassment }(\mathrm{SH}) \text { and gender } \\
\text { bias (GB) occurred frequently to women, } \\
\text { particularly while in training. }\end{array}$} & $\begin{array}{l}\text { "I get a lot of comments about my marital status on either end, when } \\
\text { I'm gonna have a baby, when I'm gonna go out. I get a lot of comments } \\
\text { about that and I don't know if that happens to the guys at all, but it's a } \\
\text { common theme in a visit." }\end{array}$ \\
\hline & $\begin{array}{l}\text { "Okay. When I was a resident, there was an attending ... known to } \\
\text { be over the line a fair amount. He would come over and put his arm } \\
\text { around me. I know a difference when, if I'm hugging a woman or a man } \\
\text { colleague, if it's a regular old hug versus something else, and this was } \\
\text { clearly not a mutual thing. So, I just looked, and I said, ...'I need you to } \\
\text { take your arm off me right now, and don't put it back." }\end{array}$ \\
\hline & [examples from women residents] \\
\hline \multirow{4}{*}{$\begin{array}{l}\text { Theme } 2 \text { : GB was often implicit, and } \\
\text { disproportionately impacted women. }\end{array}$} & $\begin{array}{l}\text { [Regarding feedback about performance on an outside service]. "It was } \\
\text { like 'great resident, except she looks disinterested on rounds, she needs } \\
\text { to smile more, or something like that." }\end{array}$ \\
\hline & [woman faculty] \\
\hline & $\begin{array}{l}\text { "... when my friends and I started applying to residency. A lot of } \\
\text { my friends had comments on their dean's letters that they were too } \\
\text { aggressive or too bossy. I think specifically to use the word bossy to } \\
\text { describe someone, you don't use that to describe a male med student." }\end{array}$ \\
\hline & [woman resident] \\
\hline \multirow{3}{*}{$\begin{array}{l}\text { Theme 3: SH had differential impact by age } \\
\text { (of the offender or offendee) and gender (of the } \\
\text { offender or offendee). }\end{array}$} & $\begin{array}{l}\text { "Anyway, the important part is... when I was younger that happened, } \\
\text { and I lacked confidence and there wasn't a culture to talk about it. I } \\
\text { didn't talk about it with my supervisor. Now I think, that was weird not } \\
\text { to have." }\end{array}$ \\
\hline & $\begin{array}{l}\text { "I've had physicians throw things at me. I had one that tried to ... } \\
\text { shut a door on my fingers, throw a phone at me. There's been lots of } \\
\text { experiences like that, not so much, definitely not here. But as a younger } \\
\text { nurse ..." }\end{array}$ \\
\hline & [examples from women faculty] \\
\hline $\begin{array}{l}\text { Theme 4: GB and SH leave lasting effects, } \\
\text { sometime mediated by moral distress. }\end{array}$ & $\begin{array}{l}\text { "I think back and be like, 'Okay, that felt really weird. Okay, was that } \\
\text { just me because we've been talking about sexual harassment and I'm } \\
\text { looking for it all the time, or is it ...? 'I feel like there's an inner check } \\
\text { that I have to go through that sometimes would keep me from saying } \\
\text { things." }\end{array}$ \\
\hline
\end{tabular}

clinician and an elderly patient). A faculty man described experiencing the behavior differently based on the woman patient's age.

It makes me feel weird ... especially if they're young ... If they're older ... I'm kind of more comfortable with it. [Faculty man]

A faculty woman recalled an encounter in which a male medical student did not associate the elderly female patient's comments with $\mathrm{SH}$ because of her age.

... I said, 'But you know what, if an elderly man said that to a woman, a female doctor, we wouldn't be okay. So were you really okay with it?' He's like, 'Oh she was just a cute little old lady.' [Faculty woman]

With patient-related SH, typically the offender was a man, and the victim a woman resident. The most commonly reported occurrence was exposure to male genitalia (eg, male patients sexualizing physical exams and having erections).

... when I was a resident in the ED ... I started doing an exam without a chaperone, and he totally had an erection. [Faculty woman]

... 'Dr [Resident's name], I have something to show you.' I walk back in, had his pants down and he was masturbating. [Resident woman]

A few examples included gender-concordant SH encounters with patients. There were discussions around what, if anything, the clinician would have done differently if the patient had been from the opposite sex.

When I was doing the breast exam [she said], 'Oh that feels good.' And I went to do the pelvic and she's like, 'You know, I'm used to sticking things in me. I'll just insert the speculum myself.' ... If a man had behaved that way, I would've stopped the exam. [Faculty woman] 
The one time I felt really uncomfortable was a very muscular, gay guy coming on to me, and I felt kinda scared, and I realized, reflecting on it, it was all about power, and that this guy was more powerful than me, and so it was the first time I got a little glimpse of what, for women, why that would be different, because it's somebody, often, more [physically] powerful than them, and that's scary. [Faculty man]

Theme 4: GB and SH Have Lasting Effects, Sometimes Mediated by Moral Distress. Participants commented on the psychological and emotional consequences of GB and $\mathrm{SH}$, experienced directly or indirectly, leaving some participants feeling threatened and unsafe.

Some women participants struggled to resolve competing ethical principles, expressing self-blame for not setting limits with patients, placing patient care before one's own psychological safety.

Bystanders or witnesses to discussions of verbal sexual harassment struggled with the impact of their lack of response in the moment.

A long time ago ... I was overhearing women interns talking about the porn that was readily shared on surgical rounds ... and how uncomfortable it made them feel ... I was mortified ... I feel guilty when I think about it. [Faculty woman]

A resident man reported concern about potentially being the offender in situations and not knowing it, such as making jokes that could be perceived as harassment.

My fear is that it gets to the point where nothing is safe and I'm afraid to make any comment whatsoever and I'm basically just a robot just going through the motions, ... there is a time and a place for comedy in medicine. Patch Adams showed us that. [Resident man]

Several women wore their white coats in hopes of preventing $\mathrm{SH}$ or GB among patients. They reported using the coat for safety, essentially, to cue the patient to their position as a doctor and to be addressed as a professional. The men in our FGs did not discuss these types of personal protective strategies.

'Yes, I may be the same age as your granddaughter, but look at this white coat, I'm a doctor.' I don't know, I've kept that barrier. [Resident woman]

I used to keep a white coat for when I would see patients like him to put on over whatever I was wearing that day. [Faculty woman]

Several faculty men expressed doubt about the existence or pervasiveness of $\mathrm{SH}, \mathrm{GB}$, and GD in the department. A male member of the research team was surprised by the frequency of the women's experience and some of the content of the results (Figure 2).

\section{Discussion}

The purpose of this study was to qualitatively identify SH, GB, and GD in an academic DFM practice. Furthermore, we aimed to identify factors that may explain the differential impact of these experiences. Most recent studies, conducted

Figure 2: Quote From Male Faculty Member of the Research Team

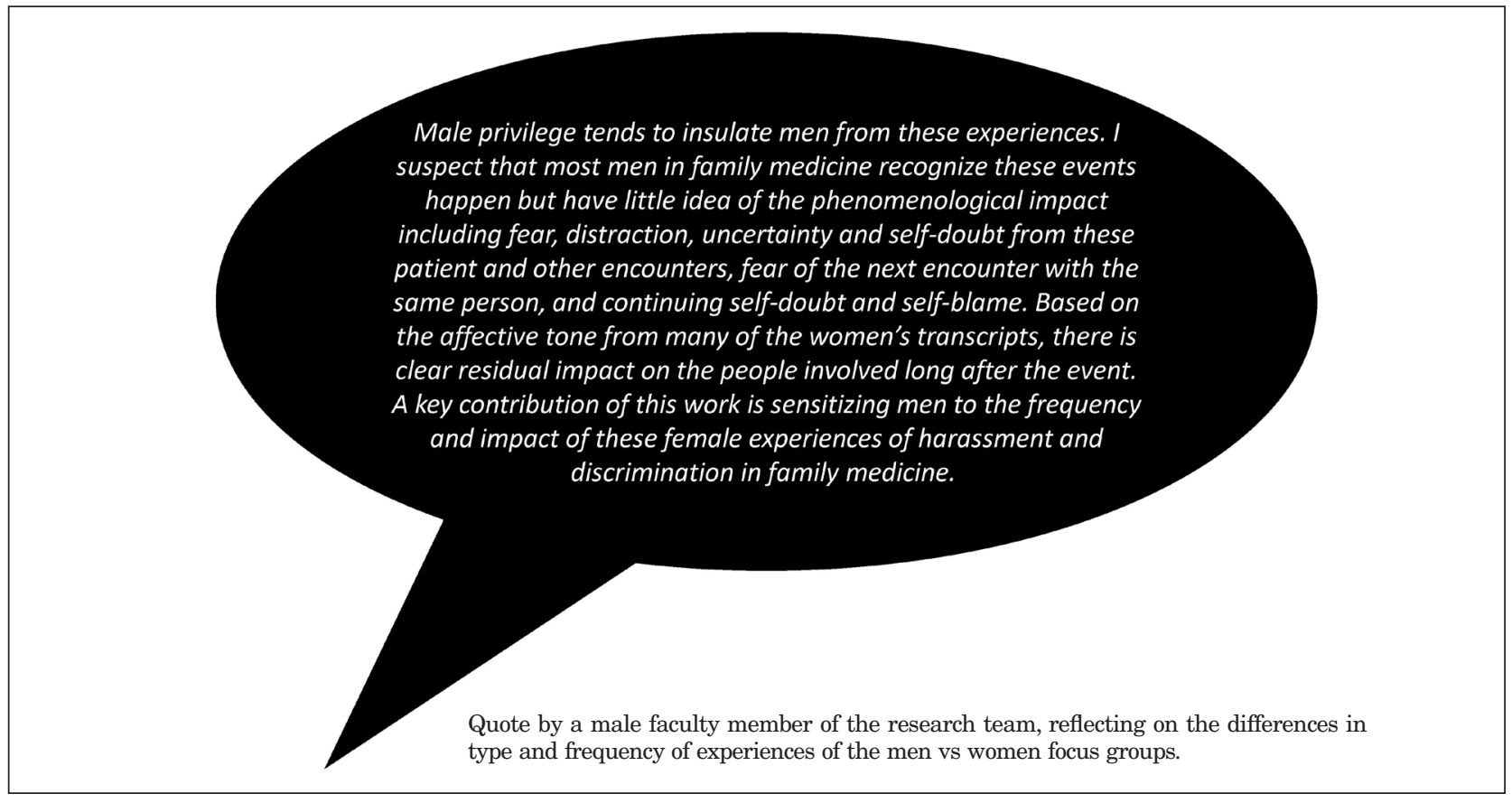


across academic department specialties, explored homogenous groups (ie, trainees only) and are quantitative. ${ }^{2,15,16}$ Similar to previous reports, our results reveal that $\mathrm{SH}$ and $\mathrm{GB}$ are common experiences. ${ }^{17-19}$ All our FGs included physical and verbal examples that involved patients, faculty, and colleagues..$^{21}$ Other studies have shown that SH and GB are underreported, ${ }^{21-23}$ and we assume that many other experiences went unspoken in our groups.

As in other studies, ${ }^{1}$ women participants experienced most of the incidents. The participants reported a range of experiences from explicit harassment to gender-based microaggression. Our finding that women clinicians use their white coats as protection by reinforcing their professional status has also been reported in the literature. ${ }^{24-27}$

Despite the increased awareness of $\mathrm{SH}$ and GB, our findings show that men and women clinicians in the same department have different experiences and perspectives regarding the scope of these issues. Men remain largely shielded from the direct impact of these situations and rarely felt unsafe. Similar to Farkas' findings, among our participants, men experienced SH differently from women and struggled to define some of these events as harassment. In our study, men were generally more accepting of SH encounters with older women patients, and felt conflicted about how to respond to younger patients who communicated sexual attraction. With these exceptions, our male FGs struggled to recall personal experiences and instead spent more time discussing hypotheticals.

\section{Limitations}

There are several limitations to our study. First, our findings are limited to one DFM in one academic medical center. However, some of the examples came from training experiences at other institutions throughout the country and are similar to those reported in the literature in other disciplines. Second, due to the voluntary nature of the FGs and challenges with time and competing priorities, approximately $68 \%$ of residents and faculty attended these groups. As a result, our findings may not represent the entirety, in terms of frequency or quality, of all our faculty and residents. Finally, we did not have a nonbinary FG, and cannot comment on the impact of $\mathrm{SH}$, GB, and GD on nonbinary gender identities.

\section{Implications}

Our findings have important implications for research and policies related to mitigating $\mathrm{SH}$ and $\mathrm{GB}$ in academic medicine. Most studies have been gender-homogenous and focused on quantitative reports of $\mathrm{SH}$ and GB, while providing less qualitative context, nuance, or impact. Our descriptions of the multiple actors, contexts, and outcomes can help leaders and policy makers tailor strategies to anticipate and address these issues in multistakeholder environments such as FM.

First, we suggest patient care policies should include mitigation strategies for reducing moral distress in clinicians. For example, a policy that requires a clinician to continue providing care to a sick patient despite their inappropriate $\mathrm{SH}$ behavior (first do no harm) may in fact be harmful to the clinician. These situations are not trivial, as moral distress has been associated with perceived lack of support from peers, burnout, and lack of involvement in decision making. ${ }^{12,13,29}$ Second, trainings should consider how to address gender stereotypes from patients, as well as responses to $\mathrm{SH}$ from gender-concordant and age-discordant patients.

We recently published participants' experiences of barriers and facilitators to reporting. ${ }^{6}$ Our next steps include department scenario training. Our goal is to develop a culture that encourages open conversations about $\mathrm{SH}$ and GB experiences, increases sensitivity through direct feedback, encourages help-seeking by any offendee, decreases distress among those directly or indirectly affected, and builds skills for all of us in responding to bias and harassment in clinical environments.

\section{Conclusions}

This study emphasizes the importance of elevating the discussion of all-too-common experiences of $\mathrm{SH}$ and GB, especially for women in academic medicine. Our study identified the presence of patients, colleagues, and faculty as perpetrators and targets of SH and GB in clinical and educational settings. Policy efforts and institutional leadership can use these findings to set clear expectations for patient, faculty, and trainee behaviors.

ACKNOWLEDGMENTS: The authors thank Kathleen Silver for assistance in preparing and submitting this manuscript.

FINANCIAL SUPPORT: Funding for this project was provided by the McDaniel-Farley Psychosocial Medicine Faculty Development Award received by Dr Russell in 2018.

PRESENTATIONS: Preliminary data analysis of this material were presented at the Society of Teachers of Family Medicine Annual Spring Conference in Toronto, Canada in April 2019; and in poster form at North American Primary Care Research Group National Conference in Toronto, Canada, in November 2019.

CORRESPONDING AUTHOR: Address correspondence to Dr Mechelle Sanders, Department of Family Medicine, University of Rochester Medical Center, 1381 South Ave, Rochester, NY 14620. 585-324-4566. Fax: 585-473-2245. mechelle_sanders@urmc.rochester.edu.

\section{References}

1. Ceppa DP, Dolejs SC, Boden N, et al. Sexual harassment and cardiothoracic surgery: \#UsToo? Ann Thorac Surg. 2020;109(4):1283-1288. doi:10.1016/j.athoracsur.2019.07.009

2. Vargas EA, Brassel ST, Cortina LM, Settles IH, Johnson TRB, Jagsi R. \#MedToo: a largescale examination of the incidence and impact of sexual harassment of physicians and other faculty at an academic medical center. $\mathrm{J}$ Womens Health (Larchmt). 2020;29(1):13-20. doi:10.1089/jwh.2019.7766

3. Fnais N, Soobiah C, Chen MH, et al. Harassment and discrimination in medical training: a systematic review and meta-analysis. Acad Med. 2014;89(5):817-827. doi:10.1097/ ACM.0000000000000200

4. Stratton TD, McLaughlin MA, Witte FM, Fosson SE, Nora LM. Does students' exposure to gender discrimination and sexual harassment in medical school affect specialty choice and residency program selection? Acad Med. 2005;80(4):400-408. doi:10.1097/00001888200504000-00020 
5. Barnes KL, Dunivan G, Sussman AL, McGuire L, McKee R. Behind the mask: an exploratory assessment of female surgeons' experiences of gender bias. Acad Med. 2020;95(10):1529-1538. doi:10.1097/ACM.0000000000003569

6. Russell HA, Fogarty CT, McDaniel SH, et al. "Am I making more of it than I should?": reporting and responding to sexual harassment. Fam Med. 2021;53(6):408-415. doi:10.22454/ FamMed.2021.808187

7. Tong A, Sainsbury P, Craig J. Consolidated criteria for reporting qualitative research (COREQ): a 32-item checklist for interviews and focus groups. Int $\mathrm{J}$ Qual Health Care. 2007;19(6):349-357. doi:10.1093/intqho/mzm042

8. Wendling AL, Gilchrist V, Ledford CJW, et al. Being Brave. Fam Med. 2021;53(6):401-403. doi:10.22454/FamMed.2021.580994

9. US Equal Employment Opportunity Commission. Preventing employment discrimination against lesbian, gay, bisexual or transgender workers (brochure). 2014. Accessed July 26 2021. https://www.eeoc.gov/laws/guidance/preventing-employment-discrimination-againstlesbian-gay-bisexual-or-transgender

10. Borkan J. Crystallization-immersion. Newbury, CA: SAGE Publications, Inc; 1999.

11. Doyle S. Member checking with older women: a framework for negotiating meaning. Health Care Women Int. 2007;28(10):888-908. doi:10.1080/07399330701615325

12. Fitzgerald LF, Drasgow F, Hulin CL, Gelfand MJ, Magley VJ. Antecedents and consequences of sexual harassment in organizations: a test of an integrated model. J Appl Psychol. 1997;82(4):578-589. doi:10.1037/00219010.82.4.578

13. Matheson K, Foster MD. Coping with the stress of gender discrimination. In: The SAGE Handbook of Gender and Psychology. London: SAGE Publications, Ltd; 2014, https:// sk.sagepub.com/reference/the-sage-handbookof-gender-and-psychology. Accessed July 28, 2021.
14. Sanderson C, Sheahan L, Kochovska S, et al Re-defining moral distress: a systematic review and critical re-appraisal of the argument-based bioethics literature. Clin Ethics. 2019;14(4):195210. doi:10.1177/1477750919886088

15. Lamiani G, Borghi L, Argentero P. When healthcare professionals cannot do the right thing: A systematic review of moral distress and its correlates. J Health Psychol. 2017;22(1):51-67. doi:10.1177/1359105315595120

16. Pololi LH, Brennan RT, Civian JT, Shea S, Brennan-Wydra E, Evans AT; Sexual Harassment Within Academic Medicine in the United States. Us, Too. Am J Med. 2020;133(2):245248. doi:10.1016/j.amjmed.2019.06.031

17. Jenner S, Djermester P, Prügl J, Kurmeyer C, Oertelt-Prigione S. Prevalence of sexual harassment in academic medicine. JAMA Intern Med. 2019;179(1):108-111. doi:10.1001/ jamainternmed.2018.4859

18. Jagsi R, Griffith KA, Jones R, Perumalswami CR, Ubel P, Stewart A. Sexual harassment and discrimination experiences of academic medical faculty. JAMA. 2016;315(19):2120-2121. doi:10.1001/jama.2016.2188

19. Li SF, Grant K, Bhoj T, et al. Resident experience of abuse and harassment in emergency medicine: ten years later. J Emerg Med. 2010;38(2):248-252. doi:10.1016/j.jemermed.2008.05.005

20. Farkas AH, Scholcoff C, Machen JL, et al. The experience of male physicians with sexual and gender-based harassment: a qualitative study. J Gen Intern Med. 2020;35(8):2383-2388. doi:10.1007/s11606-020-05695-4

21. Wayne J. Disentangling the power bases of sexual harassment: comparing gender, age, and position power. J Vocat Behav. 2000;57(3):301325. doi:10.1006/jvbe.1999.1750

22. Miedema B, MacIntyre L, Tatemichi S, et al How the medical culture contributes to coworker-perpetrated harassment and abuse of family physicians. Ann Fam Med. 2012;10(2):111-117. doi:10.1370/afm.1341
23. Wyss H, Vermeesch A. Inappropriate patient sexual behavior in nursing education. University of Portland. Pilot Scholars. 2019;2(1):1-2.

24. Ziádee P, Gordon SP. Preparing new clinicians to identify, understand, and address inappropriate patient sexual behavior in the clinical environment. J Phys Ther Educ. 2013;27(2):714. doi:10.1097/00001416-201301000-00003

25. Petrilli CM, Mack M, Petrilli JJ, Hickner A, Saint S, Chopra V. Understanding the role of physician attire on patient perceptions: a systematic review of the literature - targeting attire to improve likelihood of rapport (TAILOR) investigators. BMJ Open. 2015;5(1):e006578. doi:10.1136/bmjopen-2014-006578

26. Irvine L, Vermilya JR. Gender work in a feminized profession: the case of veterinary medicine. Gend Soc. 2010;24(1):56-82. doi:10.1177/0891243209355978

27. Keenum AJ, Wallace LS, Stevens AR. Patients' attitudes regarding physical characteristics of family practice physicians. South Med J. 2003;96(12):1190-1194. doi:10.1097/01. SMJ.0000077011.58103.C1

28. Rehman SU, Nietert PJ, Cope DW, Kilpatrick AO. What to wear today? Effect of doctor's attire on the trust and confidence of patients. Am J Med. 2005;118(11):1279-1286. doi:10.1016/j. amjmed.2005.04.026

29. Morley G, Ives J, Bradbury--Jones C, Irvine F What is 'moral distress'? A narrative synthesis of the literature. Nurs Ethics. 2019;26(3):646662. doi:10.1177/0969733017724354 